Kansas State University Libraries

New Prairie Press

\title{
OBTAINING MODELS FOR ALFALFA, SORGHUM, AND WHEAT RESIDUE DECOMPOSITION
}

H. H. Schomberg

T. W. Popham

Follow this and additional works at: https://newprairiepress.org/agstatconference

Part of the Agriculture Commons, and the Applied Statistics Commons

\section{(c) (1) $\Theta$}

This work is licensed under a Creative Commons Attribution-Noncommercial-No Derivative Works 4.0 License.

\section{Recommended Citation}

Schomberg, H. H. and Popham, T. W. (1994). "OBTAINING MODELS FOR ALFALFA, SORGHUM, AND WHEAT RESIDUE DECOMPOSITION," Conference on Applied Statistics in Agriculture. https://doi.org/ $10.4148 / 2475-7772.1359$

This is brought to you for free and open access by the Conferences at New Prairie Press. It has been accepted for inclusion in Conference on Applied Statistics in Agriculture by an authorized administrator of New Prairie Press. For more information, please contact cads@k-state.edu. 


\title{
Obtaining Models for Alfalfa, Sorghum, and Wheat Residue Decomposition
}

H. H. Schomberg, USDA-ARS, Conservation and Production Laboratory, Bushland, TX

T. W. Popham, USDA-ARS, Southern Plains Area, Biometrician, Stillwater, OK.

\begin{abstract}
Crop residues provide an economical means for controlling wind and water erosion in addition to being a valuable source of plant nutrients. As residues decompose they lose nutrients, mass and the ability to protect the soil surface from erosive forces. The research was designed to evaluate rates of residue decomposition of sorghum, wheat and alfalfa on the soil surface and buried, in five soil moisture regimes. Moisture was applied to soil by line source irrigation and bags containing crop residues were retrieved and analyzed across time. Thus, observations were repeated in both space and time.

Wieder and Lang (1982) reported that mass-loss over time was modeled well by the negative exponential. Because residue can be divided into fast (labile) and slow (recalcitrant) decomposing fractions, the double exponential is suggested. Assuming the ratio of labile to recalcitrant is constant for a crop regardless of soil moisture, and whether on the surface or buried, it would be sufficient for each crop to fit a set of simultaneous non-linear functions with three parameters, a constant $A$ (proportion labile) over all equations with different $k_{1}$ 's (labile fraction decomposition rates) and $k_{2}$ 's (recalcitrant decomposition rates) for soil moisture levels and whether buried or unburied.

For alfalfa the results were consistent with the above theory. For wheat and sorghum data holding $A$ constant over all environments resulted in $k^{\prime} s>0$. Convergence of the estimations process could not be obtained when forcing $k^{\prime} s \leq 0$. The single exponential provided a satisfactory model of decomposition, but without the advantage of separating the residues into labile and recalcitrant fractions. The inability to obtain estimates using the double exponential apparently resulted from an insufficient observation period. The recalcitrant fraction of the surface residues of these crops had not disappeared after more than a year.
\end{abstract}

\section{INTRODUCTION}

Crop residue is considered a valuable resource in conservation tillage cropping systems (Unger and McCalla, 1980). Residues provide nutrients to subsequent crops and when left on the soil surface protect soils from wind and water erosion. Microbial decomposition of crop residues releases nutrients but also decreases soil cover (Parr and Papendick, 1978). USDA-ARS scientists are involved in developing new technologies for predicting soil loss from wind and water (Foster, 1991; Hagen, 1991; Laflen et al., 1991). The new systems are daily time step simulation models using multiple submodels to predict changes in soil physical and chemical properties, climate, vegetation and soil loss due to erosion. Because soil cover is a critical component of the soil loss process, accurate estimates of cover provided by crop residues are needed for modeling of erosion.

Microbial activity in decomposing residues is controlled by substrate availability, temperature, and water potential (Stott et al., 1986). Laboratory studies show that water and temperature have a greater effect during early stages of decomposition when soluble 
$\mathrm{C}$ and $\mathrm{N}$ compounds are readily available (Stott et al., 1986), but $\mathrm{C}$ and $\mathrm{N}$ availability become major limiting factors during later stages (Knapp et al., 1983). Relationships developed for temperature and water influences on decomposition rates in the laboratory have been used to predict residue decomposition in the field (Stroo et al., 1989).

Wieder and Lang (1982) listed definitions of the decomposition process: residue mass present at time $t, Y=f(t)$; absolute decomposition rate, $\delta Y / \delta t$; and relative decomposition rate, $\delta Y / \delta t Y$.

\section{Potential functions for modeling the decomposition process.}

Linear, $Y=C+k t$; the implicit assumption of a constant decomposition rate is known to be inappropriate.

Quadratic, $\quad Y=C+k_{1} t+k_{2} t^{2}$; Wieder and Lang (1982) state, "If the objective of curvefitting is to obtain estimates of decay constants or to derive empirical expressions of the subsequent modeling of organic matter accumulation, it is imperative that the model be fitted with the restriction that at time $t=0$ all of the initial litter is present." It is almost certain that the intercept will not be fitted so that all residue is present at $t=0$.

Asymptotic, $\quad Y=C+(1-C) e^{-k t}$; similar to single exponential discussed below, it has the capability of estimating the fraction which remains when no further decomposition takes place. However, it is assumed that residues of crops disappear completely if observation continues for a sufficient length of time.

Power, $Y=C t^{k}, k<C$; this function has the appropriate form but goes to infinity for time $=0$ which is undesirable because we wish to have all residue present at $t=0$.

Single Exponential, $\quad Y=e^{-k t} ;$ mass loss from plant residues, expressed as fraction of the initial mass remaining, is best represented and analyzed as negative exponential equations Wieder and Lang (1982). The first order rate loss equation, estimates mass remaining at time $t$, as a function of the initial mass, time, and the crop specific decomposition rate coefficient $k$ (Olsen, 1963; Jenny, 1949). The underlying assumption is that absolute decomposition rate decreases linearly as the substrate remaining declines (Wieder and Lang, 1982). This assumption follows intuitively from the fact that soluble compounds such as sugars, starches, and proteins decompose rapidly while cellulose, lignin, and waxes are more resistant to decomposition. Over time, differences in decomposition between the residue components will result in remaining material having greater resistance to microbial activity.

\section{Double Exponential, $\quad Y=A e^{-k_{1} t}+(1-A) e^{-k}$}

Differences in decomposition rates between residue components have led to development of models that partition the biomass between labile (rapid, 6 months to 1 year) and recalcitrant (slow, greater than 1 year) decomposable fractions. Total decomposition can be represented by the double exponential, where $A$ represents the labile fraction of the initial material with rate coefficient $k_{1},(1-A)$ represents the recalcitrant fraction with decomposition rate $k_{2}$, and the labile and recalcitrant fractions sum to one. 
Simultaneous Double Exponential Equations, $\quad Y_{p, w}=A e^{-k_{1, p, w} t}+(1-A) e^{-k_{2, p, w} t}$

where $p=$ surface or buried, and $w=$ moisture levels $1, \ldots, 5$. An advantage of using the double exponential model; by defining the proportions of slow and fast decomposing material, differences between $k$ values for residues decomposing in multiple environments can be used to evaluate environmental effects on decomposition (Wieder and Lang, 1982, Wieder et al., 1983). Mass loss comparisons between residue treatments can be made using covariance analysis (Snedecor and Cochran, 1978; Wieder and Lang, 1982) by logtransformation with a non-fixed intercept. With repeated measures data, if response curves are developed to describe effects over time, the parameters can then be analyzed by analysis of variance to compare treatment effects (Littell, 1989).

Water and temperature relationships developed in laboratory studies should be evaluated with data collected under field conditions for applicability to long-term prediction. Multilocation studies specifically designed to sample a range of environments increase the time required for plot establishment, maintenance, and data collection, and require duplication of climate monitoring equipment. The line-source sprinkler system (hereafter designated line-source) was originally developed to study interactions of water stress with secondary factors such as fertility or genotype on crop growth (Hanks et al., 1976). The line-source provides a continuous gradient of water perpendicular to the irrigation line across a plot area. The numerous environments thus created can be used for evaluating at one location the influence of water on microbial activity.

Water level treatments in line-source studies may be repeated parallel to the linesource in blocks, but usually only one line-source is used and there is no true replication of this main effect. Problems of statistical analysis of line-source data have been addressed by Hanks et al., (1980), Johnson et al., (1983), and more recently by Fernandez (1991) who suggests that repeated measures analysis provides a more robust approach compared to the multivariate approach presented by Johnson et al., (1983).

Our objective was to evaluate use of the double exponential model to quantify environmental influences on residue decomposition as indicated by Wieder and Lang (1982) and to compare its utility to the single exponential model. We proposed to evaluate changes in $k$ values (differences in decomposition) across water treatments and placements using regression analysis.

\section{MATERIALS AND METHODS}

Field Experiment (Data collection). The data were collected from a line-source experiment on decomposition and $\mathrm{N}$ dynamics of buried or surface-placed alfalfa, (Medicago sativa L.), grain sorghum [Sorghum bicolor (L.) Moench], and winter wheat (Triticum aestivum L.) residues over a 12-mo period (Schomberg et al., 1994). Crop residues in fiberglass bags were placed on the surface or buried at $120 \mathrm{~mm}$ in Pullman clay loam (fine, mixed, thermic Torrertic Paleustoll) at Bushland, TX. Water regime treatments were created by placing the bagged residues at five distances perpendicular to the line-source in 3 blocks. The buried and surface placements gave us essentially ten water regimes for residue decomposition. Irrigation was applied frequently during the 
summer and fall. One bag of residue from each plot was collected at each sampling date (7 dates) during the year for determination of ash free dry weight remaining.

Model Fitting. The fraction of initial mass remaining at each harvest date was used to estimate parameters of the double exponential model using the MODEL procedure in SAS $\backslash E T S$ (SAS Inst. Inc., 1988). Ten equations (simultaneous double-exponential), one for each water regime-placement combination were fit for each crop residue, separately, using the SUR option of PROC MODEL. The independent variable was number of days in the field $(t)$ and the dependent variable was fraction of biomass remaining $(Y)$. Estimation of readily decomposable $(A)$ and resistant $(1-A)$ fractions were obtained by simultaneous estimation across all ten decomposition environments while the parameters $k_{1}$ and $k_{2}$ were fit for each environment (water regime-placement). The fixed intercept single exponential $k$ values were also estimated using PROC MODEL.

Analysis of Variance. The influence of water treatments on decomposition rate coefficients $\left(k^{\prime} s\right)$ were evaluated as repeated measures using the total amount of water applied to each water regime as quantitative factors. In a line-source sprinkler experiment irrigation levels are systematically arranged without randomization (repetition in space) and valid univariate tests of irrigation effects are available only when certain conditions are met (Fernandez, 1991). Repeated measures analysis is used to evaluate treatment effects where the data are collected from the same sample units at several points in time or space (Littell, 1989). Because the $k$ values are rates over time the repeated measures model does not include time. It does have crop residue type and placement as main effects, the interaction of crop residue type with placement, with water (irrigation level) as a repeated effect and all the interactions of water with main effects crop residue type and placement. The repeated measures analysis provides an evaluation of the interactions (linear, quadratic, cubic) between water, crop residue type, and placement. Linear regressions were developed describing the effect of cumulative water on rate of residue decomposition where significant interactions were indicated.

\section{RESULTS}

Parameter estimates were made for the double exponential model for each water regime, crop and placement. The fitting process and results were different between the three residue types.

Alfalfa were easily fit by the double exponential model. The rapidly decomposable fraction was estimated as 0.78 of the residue (Table 1). In most cases, the rate of decomposition for the readily decomposable fraction was approximately ten times faster than that of the resistant fraction. For surface residues in the third and fourth water regimes, the faster decomposition rate was estimated for the 1-A fraction or the smaller of the two decomposable fractions. Although this result is greatly different from the other placements, it might be expected if the fitting process identified the fraction of residue that is water soluble and therefore subject to leaching. Why this occurred with only these two locations and not for wetter water regimes is unclear and unexpected. Perhaps in the wetter regimes rapid decomposition and leaching occurred simultaneously thereby masking the result found with the third and fourth water regimes. Adjusted $R^{2}$ values for all alfalfa data were greater than .92 ; with buried residue the adjusted $R^{2}$ values were 
greater than .95 .

Sorghum surface residues had greatly different patterns of decomposition from the buried residues (Figs. 1 and 2). Buried residue decomposition followed closely an exponential while the surface residues had a more linear loss of biomass. The simultaneous double exponential model failed to accommodate this wide difference in decomposition patterns (Table 1). Model convergence occurred at 0.7 but none of the $k_{2}$ 's were significant. The labile fraction was estimated as .80 .

We hypothesized from the observed decomposition patterns of surface and buried residues that estimation of the surface decomposition rates of the recalcitrant fraction (surface $k_{2}^{\prime} s$ ) might be overly influencing estimation of the other parameters. Since surface $k_{2}$ 's were not significantly different from zero, we re-estimated the model parameters by fixing surface $k_{2}{ }^{\prime} \mathrm{s}=0$. This resulted in model convergence at 0.0001 . However, the buried decomposition rates of the recalcitrant fraction (buried $k_{2}{ }^{\prime} s$ ) remained not significantly different from zero. The adjusted $R^{2}$ for the surface residues increased from .44 to .78 averaged across the five water regimes. Although estimates of the buried $k_{2}$ 's changed, the adjusted $R^{2}$ did not. Estimates of labile fraction decreased to 0.76 when surface $k_{2}{ }^{\prime} s=0$.

The sorghum data were fitted a third time with the restriction that both the surface and buried $k_{2}{ }^{\prime} s=0$. There was little change, except the estimate of the labile fraction increased to .86 .

Graphic representation of the data using the three double exponential models and the single exponential model gave additional insight into the adequacy of the different models (Figs 1 and 2). There was good agreement between observed and predicted data for the buried sorghum residue decomposition with all three variations of the double exponential model. The double exponential closely estimates the mean of the observed data at each sampling date even when the $k_{2}$ 's are set equal to zero. The single exponential model under-predicted biomass loss during the early sample period while it over-predicted biomass loss near the end of the sampling period. The double exponential model gave a more realistic imitation of biomass loss by identifying a slowly decomposable fraction or in the case of this experiment a non-decomposable fraction.

Estimates of model parameters for surface residues were similar between all four models for most of the water regimes. Residues in the second water regime had uncharacteristic estimates of $k_{2}$ relative to all other treatments (Table 1 and Fig. 2). Difference between the $k_{l}$ 's among the four models were small. These results contrast with those from the buried residues primarily due to the limited biomass loss that occurred from the surface residues. A greater period of time would have been required for surface residues to lose the same amount of biomass as the buried residues.

Wheat results were similar to model fitting results with sorghum (Figs. 3 and 4). Estimated buried and surface $k_{2}$ 's were not significantly different from zero, with the surface $k_{2}{ }^{\prime} s<0$. Negative values indicated a trend of the resistant fraction to increase which may have been due to a limitation of the residue cleaning process, or may be attributed to accumulation of microbial biomass within the residues. Examination of residues at each harvest indicated an accumulation of fungal hyphae in both surface and buried residues. This microbial biomass was not removable from the residues. A second 
contribution may have been variability in estimation of ash free dry weight due to accumulation of soil and the sample size used for the ashing process. These effects should have been about equal for all residues except wheat residue on the soil surface accumulated soil inside the straw to a greater extent than sorghum or alfalfa. Adjusted $R^{2}$ values were in the range of .77 to .99 . The estimate of the labile fraction was 0.84 .

Model parameters were fit a second time with $k_{2}$ 's equal to zero. Buried $k_{2}$ 's were significantly different from zero. Adjusted $R^{2}$ values changed very little while estimates of the labile fraction decreased to 0.64 , which was less than expected. Since the buried $k_{2}$ 's were not significantly different from zero in the first parameter estimation, a third estimation of model parameters was evaluated with all $k_{2}$ 's equal to zero. Again, $R^{2}$ values changed very little. However, estimation of the labile fraction was a more reasonable 0.86 .

\section{DISCUSSION}

A primary objective was to quantify the influence of water regime on residue decomposition rates. The modeling results gave us three options for further evaluation of water regime effects on residue decomposition.

(1) Regress water applied vs the double exponential $k_{1}$ 's for the model where all $k^{\prime}$ 's were calculated and predict $k_{2}$ from $k_{1}$. This was not appealing since the $k_{2}{ }^{\prime}$ s were not significantly different from zero for $2 / 3$ of our data and any relationship developed would be suspect.

(2) Regress water applied vs the double exponential $k_{1}$ 's where only the $k_{1}$ 's were fit. This seemed logical since the graphs of the observed and predicted values indicated a better fit for the buried data when the double exponential model was used compared to the single exponential model.

(3) Regress water applied vs the single exponential $k_{l}$ 's. This approach is presented in Schomberg et al (1994). The approach is conservative in that only one parameter is derived from the data.

We pursued option two, where a labile fraction, $A$, is simultaneously estimated across environments for each residue. The $A$ values from model 3 in table 1 were used for wheat and sorghum while an $A$ value of 0.92 was calculated for alfalfa. New $k_{1}$ 's were determined for each crop by placement by water regime by replication using the OLS option in PROC MODEL. Water regime and placement effects on $k_{1}$ were evaluated by repeated measures analysis (water regime is the repeated variable). Where significant water regime effects were determined, regression was used to quantify the relationship between water applied and $k_{1}$.

The repeated measures analysis indicated the data did not conform to the conditions required for univariate analysis. The multivariate, and linear and quadratic contrast output from the repeated measures analysis were used to evaluate water regime interactions with crop and placement. A significant three way interaction was present which the contrast analysis indicated was linear. Regression parameters relating water applied versus decomposition rate, $k_{1}$, are given in Table 2. Model parameters are given for the double and single exponential models. The slopes and intercepts were significant for all crops and placements when using $k$ values from the single exponential model. This was not the case for the double exponential model where the intercepts were not 
significant for alfalfa buried, sorghum buried, and sorghum surface. In theory, the decomposition rate should be zero when no water is applied; however, the smallest water treatment in this study received $310 \mathrm{~mm}$ water and so further extrapolation below this value would be discouraged. Both sets of data indicate that decomposition increases with the amount of water and the influence was greater for buried residues. Relative differences between $k$ values from the two models are small and are consistent between residue types. Water effects on surface and buried residues were confounded to degree with the water treatments since buried residues are in an environment that dries more slowly than that of the surface placed residues.

The proposed evaluation of environmental influences was limited in this analysis by several factors. The greatest factor being the limited time period that was allowed for the decomposition of surface residues. Fitting of the double exponential was not possible with the surface residue until it was modified to accommodate the data. Partitioning the residues between fast and slow decomposition components, however gave a better fit of the data. The regression analysis helped determine a meaningful relationship between water application and residue decomposition rate but this information needs further evaluation with other data sets before it is used in the modeling of residue decomposition.

\section{REFERENCES}

Fernandez, G. C. J. 1991. Repeated measure analysis of line-source sprinkler experiments. Hort. Sci. 26:339-342.

Foster, G. R. 1991. Advances in wind and water erosion prediction.J. Soil and Water Conservation 46:27-29.

Hagen, L. J. 1991. A wind erosion prediction system to meet user needs. J. Soil and Water Conservation 46:106-111.

Hanks, R. J., J. Keller, V. P. Rasmussen, and G. D. Wilson. 1976. Line source sprinkler for continuous variable irrigation-crop production studies. Soil Sci. Soc. Am. Proc. 40:426-429.

Hanks, R. J., D. V. Sission, R. L. Hurst, and K. G. Hubbard. 1980. Statistical analysis of results from irrigation experiments using the line-source sprinkler system. Soil Sci. Soc. Am. J. 44:886-888.

Jenny, H., S. P. Gessel, and F. T. Bingham. 1949. Comparative study of decomposition of organic matter in temperate and tropical regions. Soil Sci. 68:419-432.

Johnson, D. E., U. N. Chaudhuri, and E. T. Kanemasu. 1983. Statistical analysis of line source sprinkler experiments and other non-randomized experiments using multivariate methods. Soil Sci. Soc. Am. J. 47:309-312.

Knapp, E. B., L. F. Elliott, and G. S. Campbell. 1983. Carbon, nitrogen and microbial biomass interrelationships during the decomposition of wheat straw: A mechanistic simulation model. Soil Biol. Biochem. 15:455-461.

Laflen, J. M., L. J. Lane, and G. R. Foster. 1991. WEPP a new generation of erosion prediction technology. J Soil and Water Conservation 46:34-38.

Littell, R. C. 1989. Statistical analysis of experiments with repeated measurements. Hort. Sci. 24:37-40. 
Olsen, J. S. 1963. Energy storage and the balance of producers and decomposers in ecological systems. Ecology 44: 322-331.

Parr, J. F., and R. I. Papendick. 1978. Factors affecting the decomposition of crop residues by microorganisms. In W. Oschwald (ed.) Crop residue management systems. Am. Soc. Agron. Madison WI. pp 101-129.

SAS Inst. Inc. 1988. SAS/ETS User's Guide, Version 6, First Edition. SAS Inst. Inc., Cary, NC.

SAS Inst. Inc. 1989. SAS/STAT User's Guide, Version 6, Fourth Edition, Volume 2. SAS Inst. Inc., Cary, NC.

Schomberg, H. H., J. L. Steiner, and P. W. Unger. 1994. Decomposition and nitrogen dynamics of crop residues: Residue quality and water effects. Soil Sci. Soc. Am. J. 58:(in press).

Snedecor, G. W. and W. G. Cochran. 1978 Statistical Methods. 6th ed. Iowa State Univ. Press. Ames, Iowa.

Stott, D. E., L. F. Elliott, R. I. Papendick, and G. S. Campbell. 1986. Low temperature or low water effects on microbial decomposition of wheat residue. Soil Biol. Biochem. 18:577-582.

Stott, D. E., H. F. Stroo, L. F. Elliott, R. I. Papendick, and P. W. Unger. 1990. Wheat residue loss from fields under no-till management. Soil Sci. Soc. Am. J. 54:928

Stroo, H. F., K. L. Bristow, L. F. Elliott, R. I. Papendick, and G. S. Campbell. 1989. Predicting rates of wheat residue decomposition. Soil Sci. Soc. Am. J. 53:91-99.

Unger, P. W., and T. M. McCalla. 1980. Conservation tillage systems. Adv. Agron. 33:1-58.

Wieder, R. K., and G. E. Lang. 1982. A critique of the analytical methods used in the examining decomposition data obtained from litter bags. Ecology. 63:1636-1642.

Wieder, R. K., J. E. Carrel, J. K. Rapp, and C. L. Kucera. 1983. Decomposition of tall fescue (Festuca elator var. arundinacea) and cellulose on surface mines and a tallgrass prairie in central Missouri, USA. J. Appl. Ecology. 20:303-321. 


\begin{tabular}{|c|c|c|c|c|c|c|c|c|c|c|c|c|}
\hline Croes & Model & Plane & Watcr Regime & DF Model & DF Error & MSE & Adjo & $\Delta$ & K. & SEK. & $\mathrm{K}_{0}$ & SEK K \\
\hline Alfalff & 1 & Buriod & 1 & 2.1 & 21.9 & .0004 & .99 & .78 & $0 \times 91$ & .0050 & .0091 & .0010 \\
\hline Alffulfa & 1 & Surffoce & 3 & 2.1 & 21.9 & .0046 & .95 & & .0051 & .0004 & .0218 & .0065 \\
\hline Alffalfa & 1 & Surfaco & 4 & 2.1 & 21.9 & .0074 & .92 & & .0046 & .0004 & .0160 & .0060 \\
\hline Sorghrun & 1 & Buriad & 2 & 2.1 & 21.9 & .0020 & .98 & .80 & .0130 & .0020 & .0006 & .0016 \\
\hline Sorghum & 1 & Surfece & 2 & 2.1 & 21.9 & .0179 & .01 & & .0031 & .0014 & $2.3 \mathrm{E}-6$ & .0024 \\
\hline Sorghum & 1 & Surface & 3 & 2.1 & 21.9 & .0139 & .56 & & .0013 & .0019 & .00002 & .0054 \\
\hline Soremmm & 2 & Buried & 2 & 2.1 & 21.9 & .00020 & .98 & .76 & .0137 & .0021 & .0014 & .0013 \\
\hline Sorgthun & 2 & Surface & 2 & 1.1 & 22.9 & .0046 & .74 & & .0019 & .0004 & . & . \\
\hline Sorztrum & 2 & Surfaco & 3 & 1.1 & 22.9 & .0080 & .75 & & .0002 & .0005 & - & . \\
\hline Sorghum & 3 & Buried & 2 & 1.1 & 22.9 & .0019 & .98 & .86 & .0122 & .0006 & - & . \\
\hline Sorgthum & 3 & Surfacoso & 2 & 1.1 & 22.9 & .0050 & .72 & & .0017 & .0001 & . & . \\
\hline Sorghum & 3 & Surface & 3 & 1.1 & 22.9 & .0080 & .75 & & .0020 & .0002 & . & . \\
\hline Sorghmun & 4 & Buriad & 2 & 1.0 & 23.0 & .0055 & .94 & 1.00 & .0082 & .0005 & . & . \\
\hline Sorghum & 4 & Surfaco & 2 & 1.0 & 23.0 & .0050 & .72 & & .0013 & .0001 & . & . \\
\hline Sorcthum & 4 & Surfice & 3 & 1.0 & 23.0 & .0077. & & & .0015. & .0001 & - & . \\
\hline Wheat & 1 & Buriad & 2 & 2.1 & 21.9 & .0020 & .98 & .84 & .0118 & .0012 & .0008 & .0015 \\
\hline Wheat & 1 & Surfaco & 2 & 2.1 & 21.9 & .0035 & .87 & & .0029 & .0005 & .0020 & . .0010 \\
\hline What & 1 & Surface & 3 & 2.1 & 21.9 & .0037 & .84 & & .0027 & .0005 & -0020 & .0011 \\
\hline Wheat & 2 & Buriad & 2 & 2.1 & 21.9 & .0020 & .98 & .64 & .0166 & .0016 & .0029 & .0005 \\
\hline Wheat & 2 & Surfaco & 2 & 1.1 & 22.9 & .0038 & .85 & & .0030 & .0011 & . & . \\
\hline Wheat & 2 & Surface & 3 & 1.1 & 22.9 & $.00 \times 10$ & .82 & & .0027 & .0004 & & . \\
\hline Wheat & 3 & Buriad & 2 & 1.1 & 22.9 & .0017 & .98 & .86 & .0127 & .0005 & & . \\
\hline Wheat & 3 & Surface & 2 & 1.1 & 22.9 & .0044 & .83 & & .0020 & .0001 & . & . \\
\hline Whear & 3 & Surface & 3 & 1.1 & 22.9 & .0044 & .81 & & .0018 & .0001 & & . \\
\hline Wheat & 4 & Buriad & 2 & 1.0 & 23.0 & .0048 & .95 & 1.00 & $.0 \times 87$ & .0005 & . & . \\
\hline Wheat & 4 & Surfaco & 2 & 1.0 & 23.0 & .0046 & .82 & & .0017 & .0001 & & . \\
\hline What & 4 & Surfice & 3 & 10 & 23.0 & .0248 & .80 & & .0015 & .0001 & & \\
\hline
\end{tabular}

1 Double Exp. All $\boldsymbol{k}_{2}$ 's estimated.

2 Double Exp. Buried $k_{2}$ 's estimated surface $k_{2}{ }^{\prime} s=0$

3 Double Exp. All $k_{2}^{\prime} s=0$.

4 Single Exp. 
Table 2. Relationship between seasonal $\mathrm{mm}$ of water received (water) and decomposition rate coefficient $(\mathrm{k})$ for buried and surface crop residues where $k=B_{0}+B_{1} *$ water(mm).

\begin{tabular}{|c|c|c|c|c|c|}
\hline Treatment & $\mathrm{B}_{0}$ & $\mathrm{~B}_{1}$ & $\mathrm{SEB}_{0}$ & $\mathrm{SEB}_{1}$ & $\mathrm{R}^{2}$ \\
\hline \multicolumn{6}{|c|}{ SINGLE EXPONENTIAL MODEL mass $=\exp (-k * t)$} \\
\hline \multicolumn{6}{|c|}{ BURIED } \\
\hline Alfalfa & .0056 & $50.5 * 10^{-6}$ & 0.0031 & $6.2 * 10^{-6}$ & 0.83 \\
\hline Sorghum & .0017 & $11.3 * 10^{-6}$ & 0.0010 & $2.1 * 10^{-6}$ & 0.69 \\
\hline Wheat & .0031 & $10.2 * 10^{-6}$ & 0.0011 & $2.2 * 10^{-6}$ & 0.62 \\
\hline \multicolumn{6}{|c|}{ SURFACE } \\
\hline Alfalfa & .00370 & $5.6 * 10^{-6}$ & 0.00047 & $1.0 * 10^{-6}$ & 0.73 \\
\hline Sorghum & .00019 & $2.5 * 10^{-6}$ & 0.00033 & $0.7 * 10^{-6}$ & 0.51 \\
\hline Wheat & .00049 & $2.1 * 10^{-6}$ & 0.00021 & $0.4 * 10^{-6}$ & 0.66 \\
\hline \multicolumn{6}{|c|}{ DOUBLE EXPONENTIAL MODEL mass $=A * \exp (-k 1 * t)+(1-A) * \exp (0 * t)$} \\
\hline \multicolumn{6}{|c|}{ BURIED } \\
\hline Alfalfa & .0084 & $60.4 * 10^{-6}$ & 0.0044 & $8.5 * 10^{-6}$ & 0.80 \\
\hline Sorghum & .0025 & $15.1 * 10^{-6}$ & 0.0015 & $2.8 * 10^{-6}$ & 0.69 \\
\hline Wheat & .0042 & $14.7 * 10^{-6}$ & 0.0016 & $3.1 * 10^{-6}$ & 0.63 \\
\hline \multicolumn{6}{|c|}{ SURFACE } \\
\hline Alfalfa & .00436 & $6.6 * 10^{-6}$ & 0.00055 & $1.1 * 10^{-6}$ & 0.75 \\
\hline Sorghum & .00025 & $2.8 * 10^{-6}$ & 0.00037 & $0.7 * 10^{-6}$ & 0.54 \\
\hline Wheat & .00065 & $2.4 * 10^{-6}$ & 0.00024 & $0.5 * 10^{-6}$ & 0.67 \\
\hline
\end{tabular}




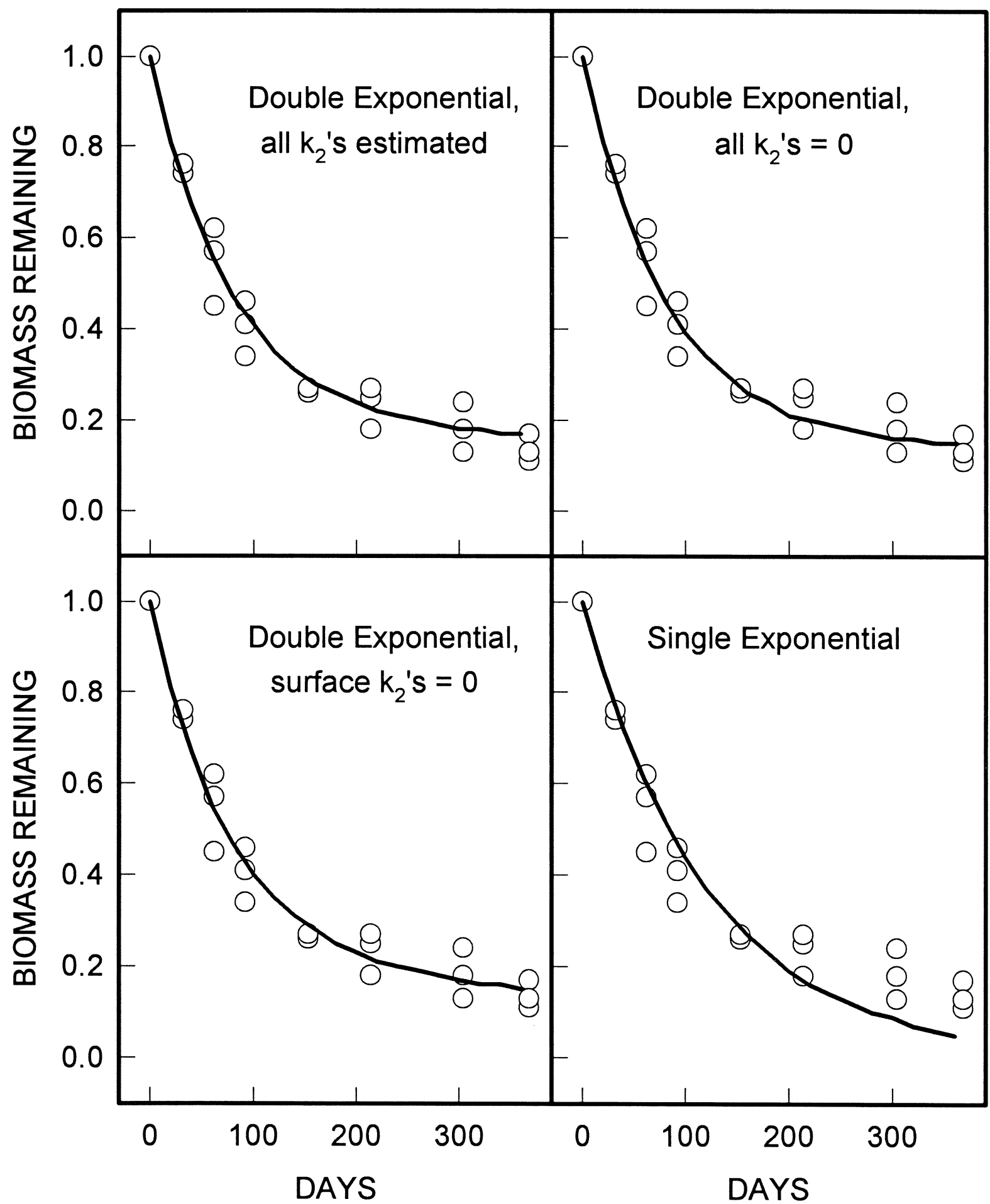

Figure 1. Sorghum, water regime 2, buried. Small circles are observations, lines are indicated fitted functions. 


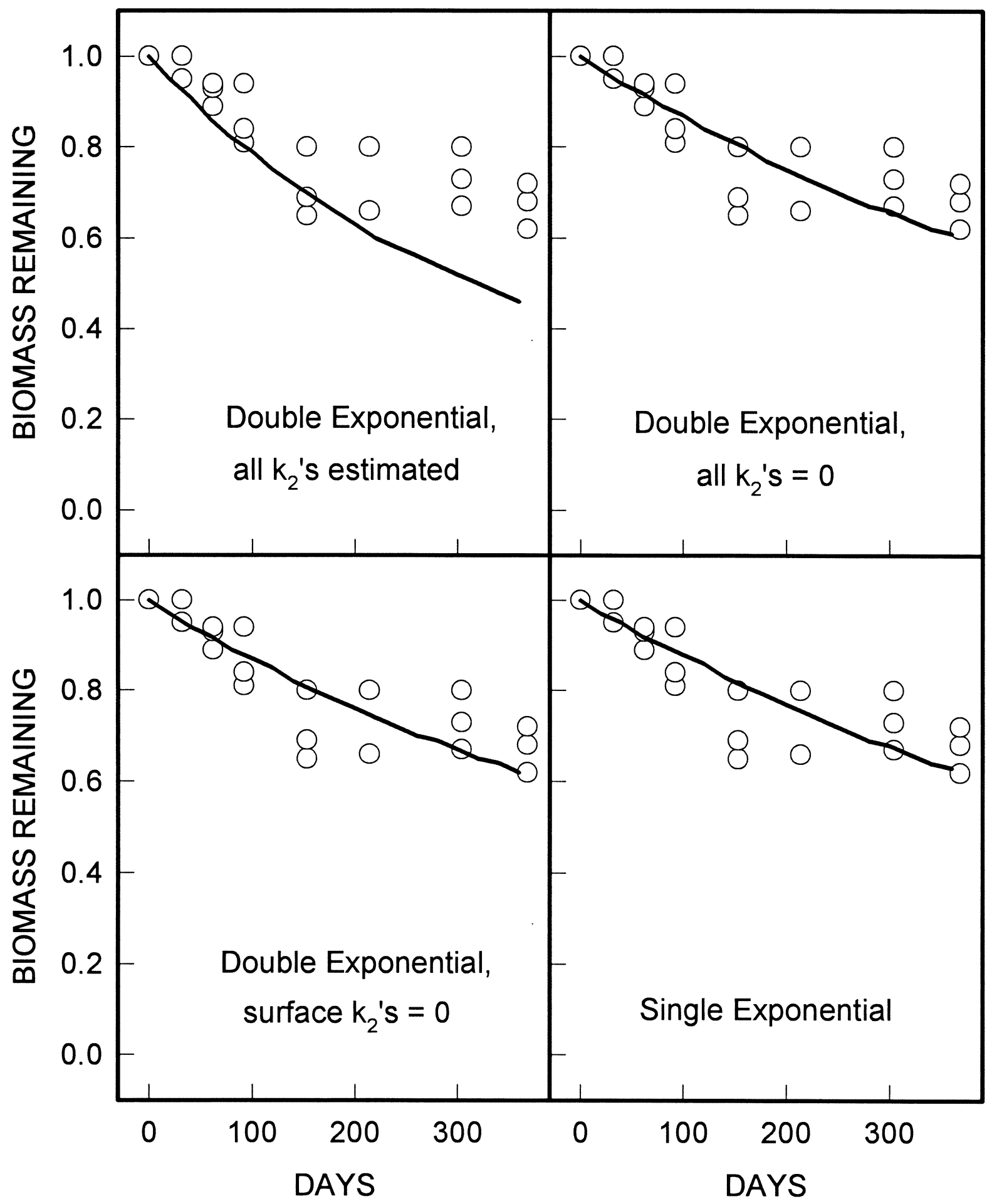

Figure 2. Sorghum, water regime 2, surface. Small circles are observations, lines are indicated fitted functions. 


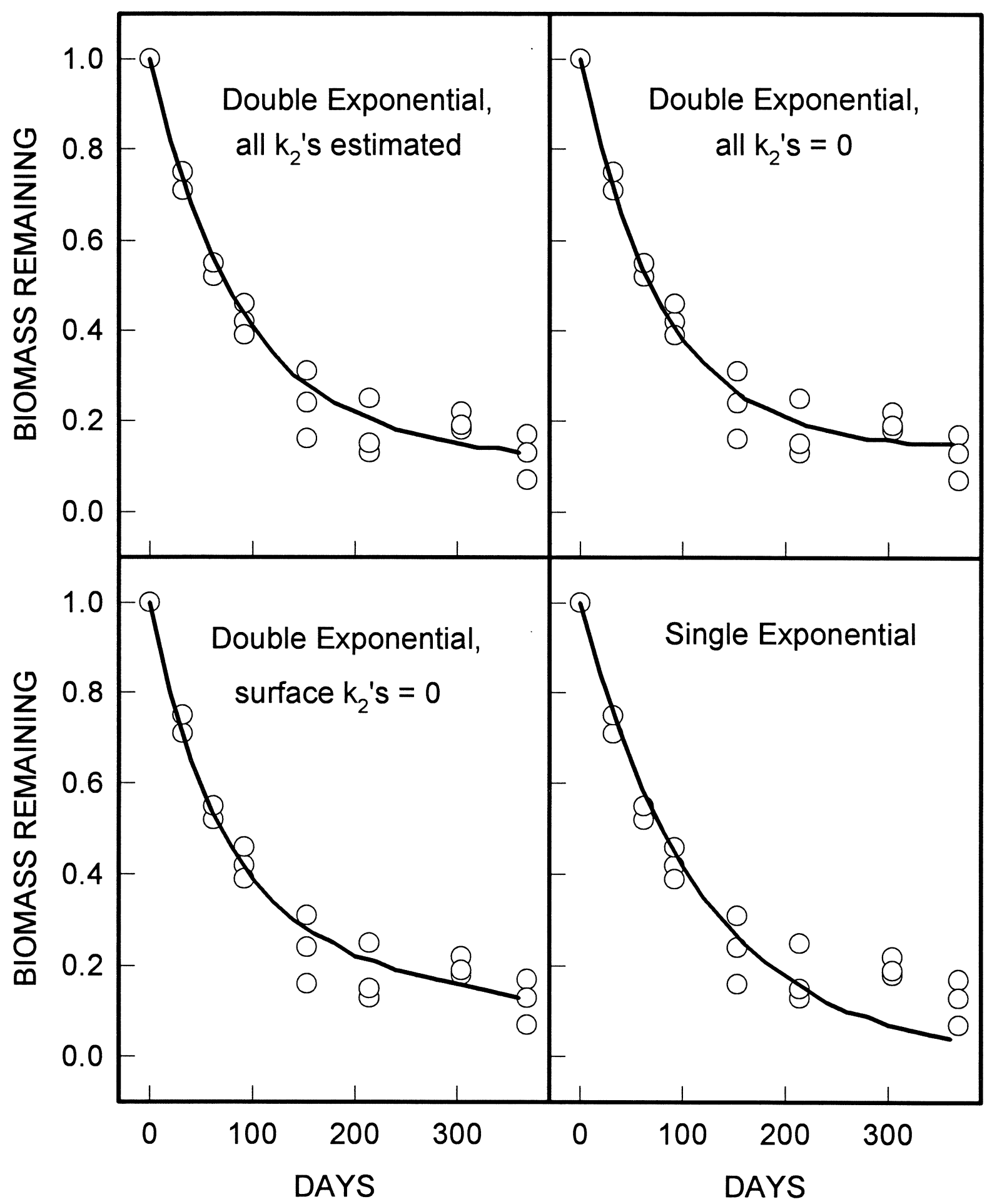

Figure 3. Wheat, water regime 2, buried. Small circles are observations, lines are indicated fitted functions. 


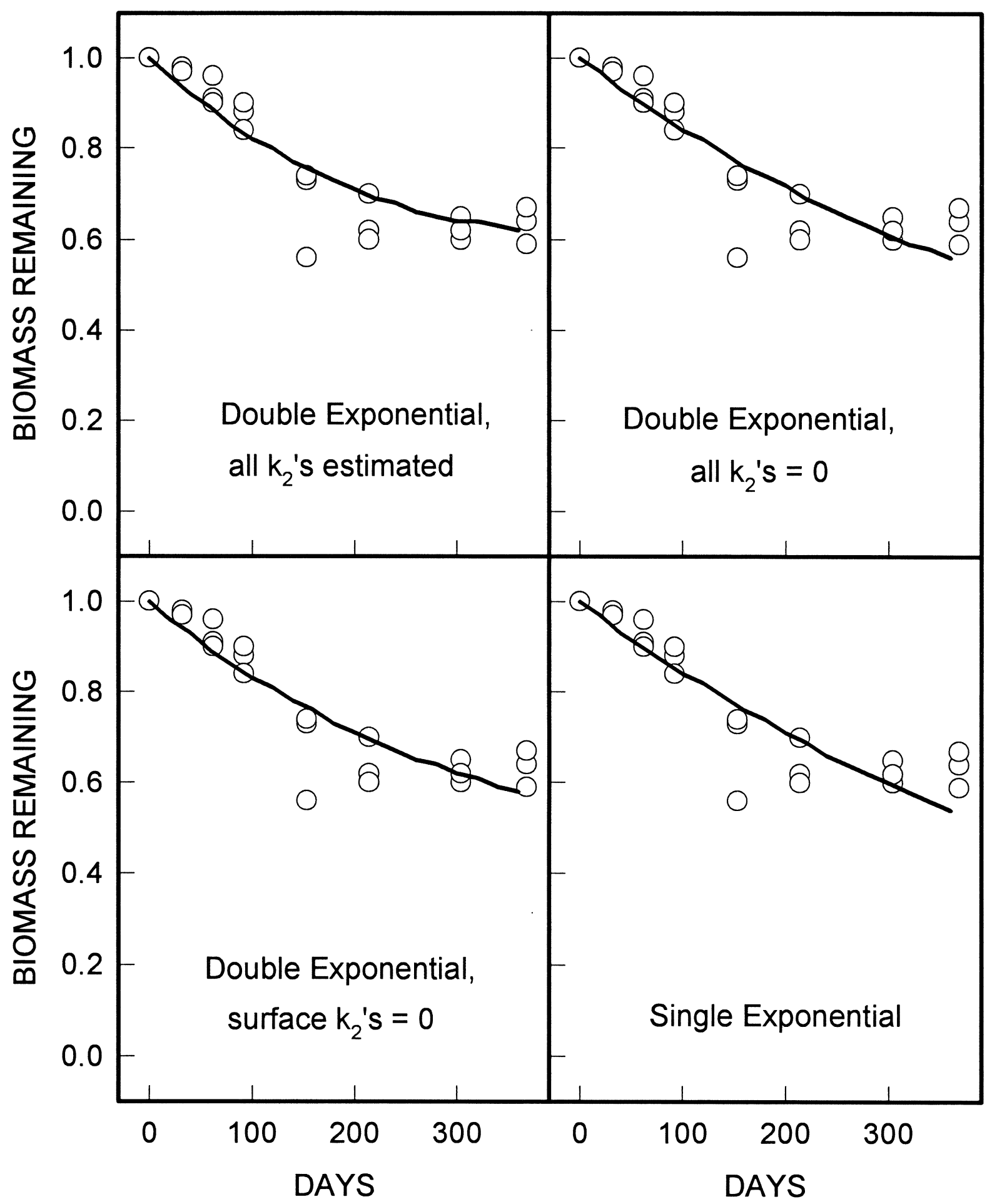

Figure 4. Wheat, water regime 2, surface. Small circles are observations, lines are indicated fitted functions. 